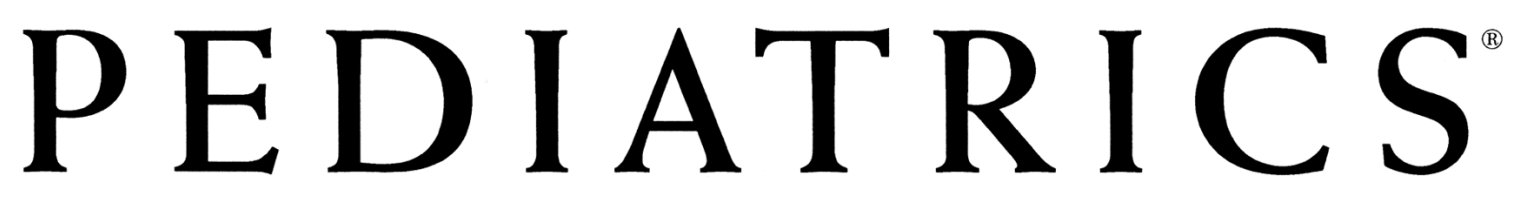

OFFICIAL JOURNAL OF THE AMERICAN ACADEMY OF PEDIATRICS

\title{
Predicting Language Change Between 3 and 5 Years and Its Implications for Early Identification
}

James Law, Robert Rush, Chantelle Anandan, Marie Cox and Rachael Wood Pediatrics 2012;130; e132; originally published online June 11, 2012;

DOI: $10.1542 /$ peds.2011-1673

The online version of this article, along with updated information and services, is located on the World Wide Web at: http://pediatrics.aappublications.org/content/130/1/e132.full.html

PEDIATRICS is the official journal of the American Academy of Pediatrics. A monthly publication, it has been published continuously since 1948. PEDIATRICS is owned, published, and trademarked by the American Academy of Pediatrics, 141 Northwest Point Boulevard, Elk Grove Village, Illinois, 60007. Copyright () 2012 by the American Academy of Pediatrics. All rights reserved. Print ISSN: 0031-4005. Online ISSN: 1098-4275.

\section{American Academy of Pediatrics}

DEDICATED TO THE HEALTH OF ALL CHILDREN ${ }^{m}$ 


\section{Predicting Language Change Between 3 and 5 Years and Its Implications for Early Identification}

WHAT'S KNOWN ON THIS SUBJECT: Early speech and language delays are risk factors for later developmental and social difficulties. It is easier to identify them retrospectively than prospectively. Population characteristics and prevalence rates make screening problematic.

WHAT THIS STUDY ADDS: Using data from a birth cohort, this study identifies predictors of language performance at 5 years and 4 patterns of change between 3 and 5 years, comparing those who change with those whose profile remains low across time points.

\section{abstract}

BACKGROUND AND OBJECTIVE: Early language delays across the preschool period have important implications for children, parents, and services raising the significance of early identification. Screening tests are an appealing solution but have proved problematic. A combined risk model would seem promising but has yet to be tested. The goal of this study was to examine the factors that predict language change in a nationally representative sample of children between 3 and 5 years when most children are identified as being in need of services.

METHODS: By using data from children $(n=13016)$ in the Millennium Cohort Study (a national UK birth cohort), linear regression was used to predict 5-year performance from 3-year test performance data coupled with sociodemographic and within-child factors and indicators of parental concern. Patterns of change were identified and logistic regression was used to predict the difference between children for whom profiles change and those for whom they do not.

RESULTS: The final model (predicting $32 \%$ of the variance) included maternal education, pattern construction, behavior, language concerns, and 3 -year vocabulary. Four change patterns were identified: one consistently low $(n=201)$, one consistently high $(n=12066)$, a group that is resilient ( $n=572)$, and one with a declining profile $(n=177)$. The models accurately predicted $71 \%$ of the declining group and $99 \%$ of the resilient group. Maternal education (odds ratio: 0.49 ) and behavior (odds ratio: $0.9)$ were significant predictors for the former and maternal education (odds ratio: 0.6 ) and pattern construction (odds ratio: 1.03) the latter. CONCLUSIONS: Early identification of delayed language remains problematic but, once identified, there are key indicators that predict which children are likely to be more or less at risk across time. The implications are discussed in terms of policy and practice. Pediatrics 2012;130:e132-e137

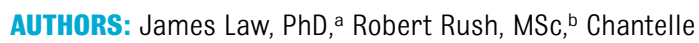
Anandan, MSc, ${ }^{\mathrm{c}}$ Marie Cox, BSc, ${ }^{\mathrm{d}}$ and Rachael Wood, $\mathrm{MSc}^{\mathrm{e}}$

alnstitute of Health and Society, School of Education, Communication and Language Sciences, Newcastle University, Newcastle-upon-Tyne, United Kingdom; ${ }^{b} Q u e e n$ Margaret University, Edinburgh, United Kingdom; 'Department of General Practice and ${ }^{d}$ College of Medicine, University of Edinburgh, Edinburgh, United Kingdom; and eInformation Services Division NHS National Services, Edinburgh, Scotland

\section{KEY WORDS}

child development, cohort studies, language screening-developmental

\section{ABBREVIATIONS}

BAS ॥-British Ability Scales Second Edition

CLL-consistently low language

IVL-increasingly vulnerable language

$\mathrm{RL}$-resilient language

TL-typical language

www.pediatrics.org/coi/doi/10.1542/peds.2011-1673

doi:10.1542/peds.2011-1673

Accepted for publication Mar 16, 2012

Address correspondence to James Law, PhD, Institute of Health and Society, School of Education, Communication and Language Sciences, Newcastle University, Newcastle-upon-Tyne, NE1 7RU United Kingdom. E-mail: james.law@ncl.ac.uk

PEDIATRICS (ISSN Numbers: Print, 0031-4005; Online, 1098-4275) Copyright (C) 2012 by the American Academy of Pediatrics FINANCIAL DISCLOSURE: The authors have indicated they have no financial relationships relevant to this article to disclose.

FUNDING: The study was funded by the Chief Scientist Office, Scotland (HSR CS017). 
Although there is good evidence for the potential long-term consequences of early language delay, ${ }^{1,2}$ the process of early identification remains a live issue. ${ }^{3-7}$ Capturing children's performance using screening tests is appealing as a concept but difficult to realize, the alternative being a hybrid model involving specific assessments of behavior and risk at differing time points. ${ }^{8,9}$ Combining performance with risk factors looks to be promising given what is known about factors associated with such delays. ${ }^{10-12}$ The role of parental concerns plays a key in this issue. ${ }^{13}$ The changing patterns of development over the early years are clearly central to the discussion, reflected in attempts to capture the difference between those children who experience consistent patterns of development and those who do not. ${ }^{14-16}$ In this study, we examined the factors that predict language change in a nationally representative sample of children between 3 and 5 years of age, a time when most children are identified as being in need of services. Two questions are addressed. To what extent is it possible to predict 5-year language performance from a range of sociodemographic and within-child predictors coupled with earlier language performance? Is it possible to characterize accurately a group whose performance changes over time relative to a group whose performance does not change?

\section{METHODS}

\section{Data Sources}

The Millennium Cohort Study ${ }^{17}$ is a national birth cohort of children born in the United Kingdom in 2000 and 2001. To date it includes four sweeps (9 months, 3, 5, and 7 years) of which the present analysis includes data collected on children at 3 and 5 years. Specifically the analysis includes all children who completed the naming vocabulary scale of the British Ability Scales (BAS II) ${ }^{19}$ at 3 and 5 years
( $n=13$ 016; males: $n=6566$ [50.4\%]; females: $n=6450$ [49.6\%]). This is an expressive language test used between 2 and 8 years in which the child is required to name pictures of objects. We controlled for nonverbal performance by using the 3-year pattern construction subscale of the BAS II.

\section{Variables}

A range of relevant predictor variables was adopted. Mother's education was used as a measure of sociodemographic status, split at above and below grade C in the national General Certificate of Secondary Education examination at 16 years of age. We identified whether children were "small for gestational age" if they were born after $>259$ gestational days weighing $<2515 \mathrm{~g}$ and whether there had been any longstanding health concerns at 3 years. Gross motor and fine motor items were included from the Denver Developmental Screening Test reported at 9 months. ${ }^{20}$ In this context, "delay" was determined, following the authors' recommendation, when an infant has not reached a milestone that $90 \%$ of infants have reached. Parental concerns about language development and hearing at 3 years were grouped into "some concerns" or "none/not applicable." Behavior was assessed by using the parent report version of the Strengths and Difficulties Questionnaire. ${ }^{21}$

\section{Analytic Strategy}

The analysis was conducted in 2 phases. In the first, we used linear regression with BAS II naming vocabulary scale at 5 years as the dependent variable. In the second, language performance was categorized at 3 and 5 years, examining the productivity figures (sensitivity, specificity, and both positive and negative predictive ability) of the 3-year naming vocabulary scale in predicting 5year vocabulary. Logistic regression was then used to examine factors associated with a series of change profiles. In each case, the candidate covariates were the same. Block 1 includes gender, maternal education, and whether the child was born small for gestational age. Block 2 adds the early identification of gross and fine motor difficulties at 10 months of age. Block 3 includes parental concerns about the child's hearing and whether the child had experienced any long-term illness. Block 4 adds the pattern construction scale from the BAS II; block 5 adds behavior; and block 6 adds whether the parent expressed any concerns about language development when the child was seen at 3 years.

All analyses were performed by using SPSS version 17.0 for Windows (SPSS Inc, Chicago, IL). Data were weighted to the UK population.

\section{Operationalizing the Groups}

In the second phase of the analysis, the BAS II naming vocabulary outcome was split into 4 groups. Following convention, ${ }^{22}$ we defined children as being language delayed if they scored less than -1.5 SDs of the weighted sample distribution of age-related normed test scores on the BAS II naming vocabulary scale. The typical language group ( $n=$ 12 066) had scores within normal limits at both 3 and 5 years. An increasingly vulnerable language (IVL) group ( $n=$ 177) had typical development at 3 years but language delay by 5 years; a resilient language (RL) group ( $n=572)$ was language delayed at 3 years but developing typically by 5 years; and a consistently low language (CLL) group ( $n=201)$ had language delay at both time points. A McNemar test demonstrated that there was a significant change in scores on the BAS II from 3 to 5 years $\left(\chi^{2}=1554.965, \mathrm{df}=1, P<.001\right)$. Mean \pm SD scores for the BAS II for the 4 groups are provided in Table 1.

\section{Modeling Steps}

A series of univariable and multivariable regression models were used to identify 
TABLE 1 BAS II Naming Vocabulary Scale at 3 and 5 Years of Age (Mean and $95 \%$ confidence intervals)

\begin{tabular}{llc}
\hline Group & \multicolumn{2}{c}{ BAS II Naming Vocabulary } \\
\cline { 2 - 3 } & \multicolumn{1}{c}{3 Years } & \multicolumn{1}{c}{5 Years } \\
\hline TL & $52.32(52.15,52.5)$ & $57.15(56.98,57.31)$ \\
IVL & $43.53(42.63,44.43)$ & $31.92(31.32,32.53)$ \\
RL & $29.78(29.4,30.15)$ & $47.01(46.39,46.65)$ \\
CLL & $27.15(26.47,27.82)$ & $29.6528 .98,30.32)$ \\
\hline
\end{tabular}

TL, typical language.

variables that were independently associated with the outcome (BAS II at 5 years) in 2 phases. At each step, attention was paid to the effects of adjusting for other variables on the regression coefficients; confidence intervals and significance levels are reported. A series of univariable regression analyses were performed to test the strength of the association of each variable with the outcome variable. Those significant at $P<.1$ were retained in the next step of the analysis. To identify the best explanatory combination, thus increasing confidence in the robustness of the final models, any variables remaining significant at the $5 \%$ level within the multivariable analyses were carried forward to the final multivariable analysis.

\section{RESULTS}

For the first phase, a decrease was seen in scores across the models for boys, being small for gestational age, early gross and fine motor delays, longstanding health conditions, and hearing concerns; the changes started significant but dropped out once and were no longer statistically significant other blocks were added (Table 2).

In the final model (model 8), whether cohort members were born small for their due date was no longer significant and the magnitude of the independent effect of the other variables was reduced. The addition of the 3 years' score again doubled the variance, to explain $32 \%$ of the variation in the BAS II at 5 years. Of this, half was accounted for by the initial BAS II scores and the remainder by the other factors, suggesting that

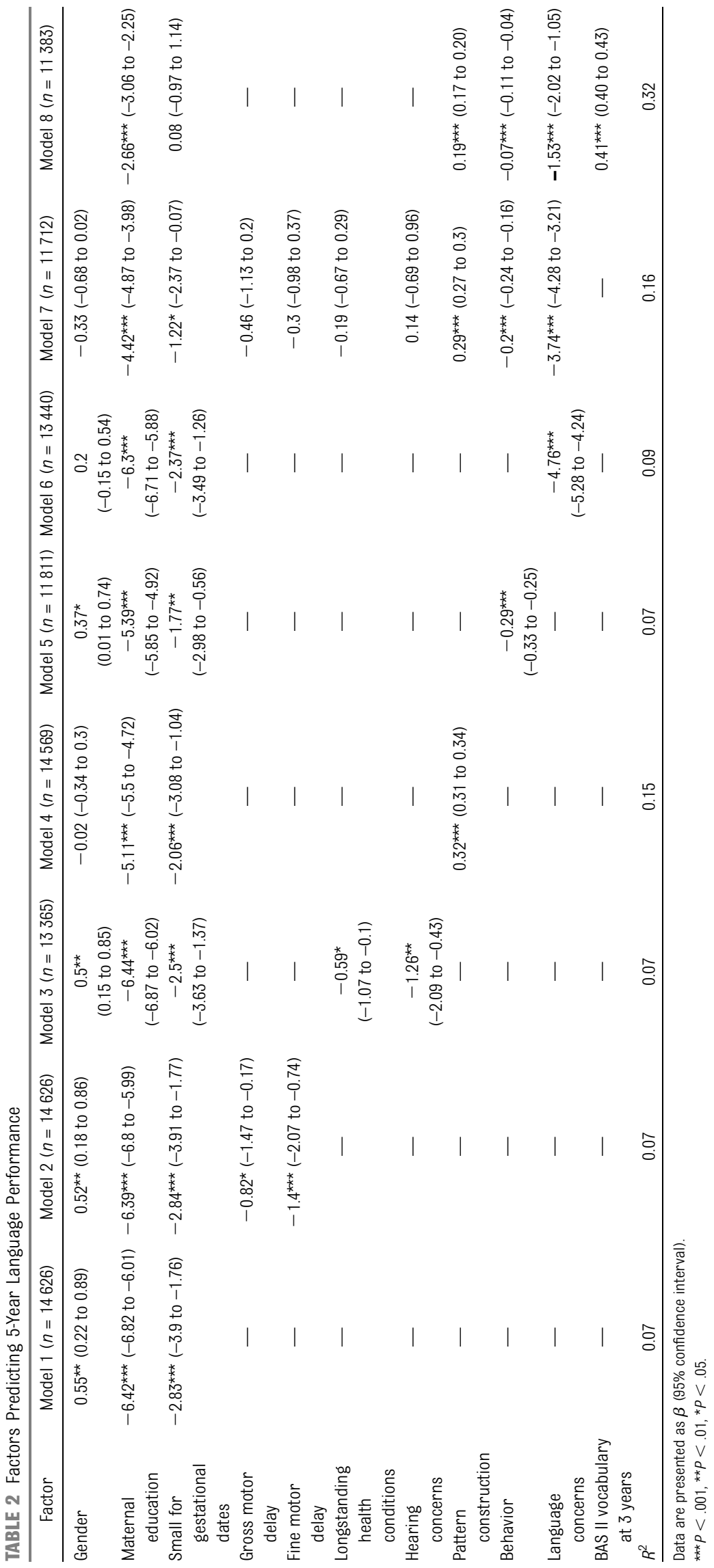


enhancing child performance with relevant history data would improve a model of early identification.

In the cross-classification presentation pattern ${ }^{3,4}$ of high specificity (0.95) and low sensitivity (0.53), where prevalence rates are relatively low, suggesting that the 3-year score was very good at determining who was not likely to have a subsequent difficulty but less accurate in predicting who was. This finding is reflected both in the positive (0.26) and negative (0.96) predictive abilities. With a threshold of -1.5 SDs, the prevalence rates were $5.9 \%$ at 3 years, dropping to $2.9 \%$ at 5 years; however, only those included at time 1 were included in time 2 .

Four patterns of change were then plotted (Fig 1). Table 4 provides the final (Table 3), we see the characteristic

model for the difference between the IVL and CLL groups.

Univariable associations indicated that only maternal education, gross motor skills, and behavior significantly distinguished between the 2 groups. Maternal educational level was consistently strongly associated across all the blocks, with those in the poor maternal education group being half as likely to be in the IVL group. When controlling for maternal education, behavior remained associated, with those with greater behavior difficulties being more likely to be in the CLL group, whereas gross motor skills dropped out of the analysis. The final model correctly predicted $57 \%$ of those in the CLL group and $71 \%$ of those whose performance declines (overall: 64\%).

TABLE 3 Cross Classification Rates Using the BAS II Naming Vocabulary Scale at 3 and 5 Years of Age

\begin{tabular}{|c|c|c|c|c|}
\hline & \multicolumn{4}{|c|}{ BAS II Naming Vocabulary Scale at 5 Years } \\
\hline & & Positive & Negative & Total \\
\hline \multirow[t]{3}{*}{ BAS II Naming Vocabulary at 3 Years } & Positive & 201 (CLL group) & 572 (RL group) & 773 \\
\hline & Negative & 177 (IVL group) & 12066 (TL group) & 12243 \\
\hline & Total & 378 & 12638 & 13016 \\
\hline
\end{tabular}

TL, typical language.

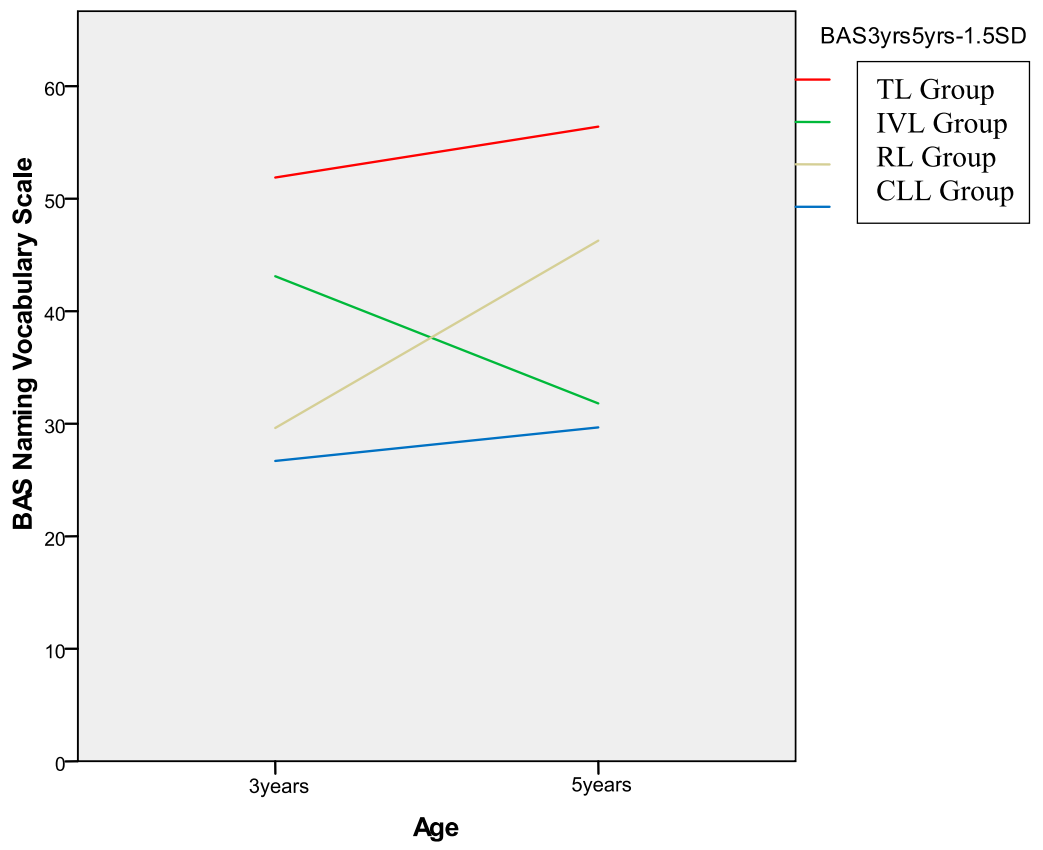

FIGURE 1

Patterns of change on the BAS II Naming Vocabulary Scale between 3 and 5 years (raw scores).
Table 5 reports comparable results for the RL and CLL groups. Univariable associations found that maternal education, gross motor skills, pattern construction, and behavior were significant $(P=.1)$. For the multivariable models, maternal education was again significantly differentiating the 2 groups, with the CLL group having mothers with the lowest educational attainment. Gross motor skills were not significant in the presence of maternal education. In model 3, pattern construction remained in the final model while behavior dropped. The capacity of these models to predict at an individual level in terms of percent correctly identified is generally reasonable although the patterns can sometimes appear anomalous. This was the case for the CLL group, of whom just $2 \%$ were correctly classified relative to the RL group, of whom virtually all were correctly classified (Table 5 ). It is important to stress that "the classification table is most appropriate where classification is the stated goal of the analysis; otherwise it should only supplement more rigorous methods of assessment of fit." 23

\section{DISCUSSION}

Our results suggest that different characteristics distinguish the increasingly vulnerable and resilient groups. In both cases, although those least likely to change had mothers with lower levels of education, the CLL group had a higher level of behavior difficulties than those whose scores subsequently drop. By contrast, it is the child's nonverbal performance that seems to trigger resilience. Both highlight the need to include supplementary within-child and environmental information when weighing risk. It seems easier to identify reduced risk in those with initial delays but less easy to identify those whose skills are likely to decrease. The findings demonstrate well the inherent problem with developmental screening. Even with a 
TABLE 4 Difference Between the CLL Group $(n=201)$ and the IVL Group $(n=177)$

\begin{tabular}{|c|c|c|c|}
\hline Factor & Model 1 & Model 2 & Model 3 \\
\hline Maternal education & $0.450^{\star \star \star}(0.298$ to 0.680$)$ & $0.452^{\star \star \star}(0.299,0.685)$ & $0.490^{\star \star}(0.302$ to 0.795$)$ \\
\hline Gross motor delay (Denver) & - & $0.485(0.233$ to 1.013$)$ & - \\
\hline Behavior (SDQ) & - & - & $0.923^{\star \star \star}(0.885$ to 0.962$)$ \\
\hline$n$ & 376 & 375 & 289 \\
\hline CLL group correct \% & 60.5 & 64.8 & 56.9 \\
\hline IVL group correct \% & 59.2 & 55.0 & 70.9 \\
\hline Overall correct \% & 59.9 & 60.2 & 64.3 \\
\hline
\end{tabular}

Data are presented as odds ratio (95\% confidence interval), $n$, or \%. Denver, Denver Developmental Screening Test; SDQ, Strengths and Difficulties Questionnaire.

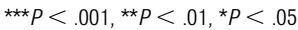

relatively strong set of predictors, the model only accounted for $32 \%$ of the variance. It is important to note that although parental report of concern does predict 5-year performance as a continuous scale, it does not distinguish changing patterns of performance.

\section{Strengths and Limitations of the Study}

The strength of this study is that it is derived from a nationally representative sample by using a well-standardized measure of expressive vocabulary and, perhaps most significantly, a measure that is repeated across the vitally important 2-year period before school entry. We carried out an analysis of different thresholds ( -1 and -2 SDs) but this proved almost identical to those in the present analysis, adding confidence to the interpretation and obviating the problem of marginal test differences between groups. It is also important to acknowledge that although many of the associations with independent factors in the logistic regression models are statistically significant, it does not mean that the resultant model necessarily classifies the groups well on the dependent variable. ${ }^{23}$

\section{Implications for Policy and Practice}

Policy makers and practitioners are faced with a dilemma. On the one hand, there is strong evidence that early language delays make a child vulnerable to later difficulties. This relationship becomes clearer as the young child moves toward compulsory schooling. ${ }^{24}$ On the other hand, results from this and many other studies suggest that the adoption of formal procedures, even measures as psychometrically robust as the BAS II, remains problematic. The data here suggest that the key is to combine child performance data, including earlier performance and both verbal and nonverbal conaspects of sociodemographic risk. But even this would be difficult if only carried out at a single time point, forcing us to conclude that there remains a strong case for the population monitoring of risk groups before the school years, current performance, together with whether conducted by pediatricians in the medical home or health visitors in community health center and that delayed language acquisition is probably one of the most useful and accessible litmus tests of early childhood well-being. Such a conclusion emphasizes the potential role for "proportionate universalism," 25 by which universal services such as screening and early identification are tailored to the level of disadvantage, not restricted to those with the highest levels of need. Our findings suggest that patterns of change in early language skills are potentially one method of differentiating such needs.

Although attention has been paid in the present analysis to significant withinchild and environmental factors, we have of course overlooked one of the most important potential environmental modifications to which children of this age are exposed; namely, early years of education and specifically speech and language therapy services. ${ }^{26}$ The latter have been shown to be effective with the type of problems that would be identified by a naming vocabulary measure, but we unfortunately have no way of knowing which children received such services. ${ }^{27}$

\section{Implications for Research}

Findings from the present analysis would warrant replication in comparable large-scale representative data sets. Better understanding of the relationship between patterns of change and the potential implications of intervention

TABLE 5 Difference Between the CLL Group $(n=201)$ and the RL Group $(n=572)$

\begin{tabular}{|c|c|c|c|c|c|}
\hline Factor & Model 1 & Model 2 & Model 3 & Model 4 & Model 5 \\
\hline Maternal education & $0.481^{\star \star \star}(0.346$ to 0.668$)$ & $0.486^{\star \star \star}(0.349$ to 0.675$)$ & $0.543^{\star \star \star}(0.385$ to 0.766$)$ & $0.526^{\star \star}(0.355$ to 0.78$)$ & $0.596^{\star}(0.396$ to 0.896$)$ \\
\hline Gross motor delay, (Denver) & - & $0.672(0.403$ to 1.12$)$ & - & - & - \\
\hline Pattern construction, (BAS II) & - & - & $1.037^{\star \star \star}(1.021$ to 1.052$)$ & - & $1.032^{\star \star \star}(1.015$ to 1.050$)$ \\
\hline Behavior, (SDQ) & - & - & - & 0.969 (0.94 to 1$)$ & $0.976(0.945$ to 1.007$)$ \\
\hline$n$ & 770 & 770 & 761 & 581 & 575 \\
\hline CLL group correct, \% & 0 & 0 & 7.4 & 0 & 2 \\
\hline RL group correct, \% & 100 & 100 & 97.6 & 100 & 99.6 \\
\hline Overall correct, \% & 74.1 & 74.1 & 75 & 76.4 & 77.5 \\
\hline
\end{tabular}

Data are presented as odds ratio (95\% confidence interval), $n$, or \%. Denver, Denver Developmental Screening Test; SDQ, Strengths and Difficulties Questionnaire. ${ }^{\star * \star} P<.001,{ }^{* \star} P<.01,{ }^{\star} P<.05$ 
would be helpful. Finally, it would be useful to explore the patterns of change at both a group and an individual level as children move through school to put figures on the burden of risk associated with early language difficulties.

\section{CONCLUSIONS}

This study is one of a small number that have used large-scale population data to examine patterns of language change

\section{REFERENCES}

1. Clegg J, Hollis C, Mawhood L, Rutter M. Developmental language disorders - a followup in later adult life. Cognitive, language and psychosocial outcomes. J Child Psychol Psychiatry. 2005;46(2):128-149

2. Law J, Rush R, Schoon I, Parsons S. Modeling developmental language difficulties from school entry into adulthood: literacy, mental health, and employment outcomes. J Speech Lang Hear Res. 2009;52(6):1401-1416

3. Law J, Boyle J, Harris F, Harkness A. Screening for speech and language delay: a systematic review of the literature. Health Technol Assess. 1998;2(9):1-184

4. Nelson HD, Nygren P, Walker M, Panoscha R. Screening for speech and language delay in preschool children: systematic evidence review for the US Preventive Services Task Force. Pediatrics. 2006;117(2). Available at: www. pediatrics.org/coi/content/full/117/2/e298

5. van Agt HM, van der Stege HA, de RidderSluiter $H$, Verhoeven LT, de Koning HJ. A cluster-randomized trial of screening for language delay in toddlers: effects on school performance and language development at age 8. Pediatrics. 2007;120(6):1317-1325

6. van der Ploeg $\mathrm{CP}$, Lanting $\mathrm{Cl}$, Verkerk $\mathrm{PH}$. Should we screen for language delay in toddlers? Pediatrics. 2008;121(6):12991300

7. van Agt HM, de Koning HJ. Should we screen for language delay in toddlers? Pediatrics. 2008;121(6):1300

8. Council on Children With Disabilities; Section on Developmental Behavioral Pediatrics; Bright Futures Steering Committee; Medical Home Initiatives for Children With Special Needs Project Advisory Committee. Identifying infants and young children with developmental disorders in the medical home: an algorithm for development surveillance and screening [published correction across time but the first, to the best of our knowledge, to do so in the context of early identification. There is evidence to suggest that early language delays point to later difficulties; however, this finding does not readily translate into identification at an individual level. Although it is possible to anticipate language performance at school entry from a relatively predictable set of factors, it would seem that, beyond

appears in Pediatrics. 2006;118(4):18081809] . Pediatrics. 2006;118(1):405-420

9. Shribman S, Bellingham K. The Child Health Promotion Programme: Pregnancy and the First Five Years of Life. Nottingham, England: Department for Children, Families and Schools; 2008

10. Desmarais C, Sylvestre A, Meyer F, Bairati I, Rouleau N. Systematic review of the literature on characteristics of late-talking toddlers. Int J Lang Commun Disord. 2008; 43(4):361-389

11. Hart B, Risley T. Meaningful Differences in the Everyday Experiences of Young American Children. Baltimore, MD: Paul Brookes; 1995

12. Joshi HE, Verropolou G. Maternal employment and child outcomes. Occasional Paper, The Smith Institute. London, UK: The Smith Institute; 2000

13. Laing GJ, Law J, Levin A, Logan S. Evaluation of a structured test and a parent led method for screening for speech and language problems: prospective population based study. BMJ. 2002;325(7373): 1152

14. Feinstein L, Bynner J. The importance of cognitive development in middle childhood for adulthood socioeconomic status, mental health, and problem behavior. Child Dev. 2004;75(5):1329-1339

15. Rice ML, Taylor CL, Zubrick SR. Language outcomes of 7-year-old children with or without a history of late language emergence at 24 months. J Speech Lang Hear Res. 2008;51(2):394-407

16. Ukoumunne OC, Wake M, Carlin J, et al. Profiles of language development in preschool children: a longitudinal latent class analysis of data from the Early Language in Victoria Study [published online ahead of print March 24, 2011].. Child Care Health Dev. doi:10.1111/j.1365-2214.2011.01234.x maternal education, those that predict risk and resilience are not necessarily the same. We could conclude that testing the language skills of 3 -year-olds is a relatively good way of establishing which children will not have later difficulties, butthere remains a need both to monitor poor performers and to improve our understanding of the mechanisms by which children's language skills falter after seeming to develop normally.

17. Millennium Cohort Study. Centre for Longitudinal Studies. Available at: http://cls.ioe.ac. uk/page. aspx? \&sitesectionid $=851$ Last accessed 15.04.12 Accessed August 11, 2011

18. Hansen K, Joshi H, Dex S. Children of the 21st century. vol. 2: The First Five Years. Bristol: The Policy Press; 2010

19. Elliott C, Smith P, McCulloch K. British Ability Scales. 2nd ed. London, UK: NFER Nelson; 1997

20. Frankenburg WK, Dodds J, Archer P, Shapiro $\mathrm{H}$, Bresnick B. The Denver II: a major revision and restandardization of the Denver DeveIopmental Screening Test. Pediatrics. 1992; 89(1):91-97

21. Goodman R. The Strengths and Difficulties Questionnaire: a research note. I Child Psychol Psychiatry. 1997;38(5):581-586

22. Tomblin JB, Records NL, Buckwalter $P$, Zhang X, Smith E, O'Brien M. Prevalence of specific language impairment in kindergarten children. J Speech Lang Hear Res. 1997;40(6):1245-1260

23. Hosmer DW, Lemeshow S. Applied Logistic Regression: Textbook and Solutions Manual. London, UK: Wiley-IEEE; 2004

24. Law J, Tomblin JB, Zhang X. Characterizing the growth trajectories of language-impaired children between 7 and 1 years of age. J Speech Lang Hear Res. 2008;51(3):739-775

25. Global Health Equity Group. Strategic review of health inequalities in England post2010 (The Marmot Review). Available at: www.ucl.ac.uk/marmotreview

26. Law J, Garrett Z, Nye C. Speech and language therapy interventions for children with primary speech and language delay or disorder. Cochrane Database Syst Rev. 2009; (3):CD004110

27. Zhang $X$, Tomblin JB. The association of intervention receipt with speech-language profiles and social-demographic variables Am J Speech Lang Pathol. 2000;9:345-357 


\section{Predicting Language Change Between 3 and 5 Years and Its Implications for Early Identification}

James Law, Robert Rush, Chantelle Anandan, Marie Cox and Rachael Wood

Pediatrics 2012;130; 132; originally published online June 11, 2012;

DOI: $10.1542 /$ peds. 2011-1673

\section{Updated Information \& Services}

\section{References}

Subspecialty Collections

Permissions \& Licensing

Reprints including high resolution figures, can be found at: http://pediatrics.aappublications.org/content/130/1/e132.full.h tml

This article cites 16 articles, 8 of which can be accessed free at:

http://pediatrics.aappublications.org/content/130/1/e132.full.h tml\#ref-list-1

This article, along with others on similar topics, appears in the following collection(s):

Development/Behavioral Issues

http://pediatrics.aappublications.org/cgi/collection/developme nt:behavioral_issues_sub

Information about reproducing this article in parts (figures, tables) or in its entirety can be found online at: http://pediatrics.aappublications.org/site/misc/Permissions.xh tml

Information about ordering reprints can be found online: http://pediatrics.aappublications.org/site/misc/reprints.xhtml

PEDIATRICS is the official journal of the American Academy of Pediatrics. A monthly publication, it has been published continuously since 1948. PEDIATRICS is owned, published, and trademarked by the American Academy of Pediatrics, 141 Northwest Point Boulevard, Elk Grove Village, Illinois, 60007. Copyright (C) 2012 by the American Academy of Pediatrics. All rights reserved. Print ISSN: 0031-4005. Online ISSN: 1098-4275.

\section{American Academy of Pediatrics \\ DEDICATED TO THE HEALTH OF ALL CHILDREN ${ }^{m}$}

